\title{
Combined effectiveness of prior and current season influenza vaccination in northern Spain: 2016/17 mid- \\ season analysis
}

J Castilla ${ }^{12}$, A Navascués ${ }^{3}$, I Casado ${ }^{12}$, J Díaz-González ${ }^{1}$, A Pérez-García ${ }^{23}$, L Fernandino ${ }^{1}$, I Martínez-Baz ${ }^{12}$, A Aguinaga ${ }^{3}$, F Pozo $^{4}$, C Ezpeleta ${ }^{3}$, Primary Health Care Sentinel Network ${ }^{5}$, Network for Influenza Surveillance in Hospitals of Navarre 5

1. Instituto de Salud Pública de Navarra, IdiSNA - Navarre Institute for Health Research, Pamplona, Spain

2. CIBER Epidemiología y Salud Pública (CIBERESP), Spain

3. Complejo Hospitalario de Navarra, IdiSNA - Navarre Institute for Health Research, Pamplona, Spain

4. Centro Nacional de Microbiología (WHO National Influenza Centre - Madrid), Instituto de Salud Carlos III, Majadahonda, Spain

5. The members of these networks are listed at the end of the article

Correspondence: Jesús Castilla (jcastilc@navarra.es)

Citation style for this article:

Castilla J, Navascués A, Casado I, Díaz-González J, Pérez-García A, Fernandino L, Martínez-Baz I, Aguinaga A, Pozo F, Ezpeleta C, Primary Health Care Sentinel Network, Network for Influenza Surveillance in Hospitals of Navarre. Combined effectiveness of prior and current season influenza vaccination in northern Spain: 2016/17 mid-season analysis. Euro Surveill. 2017;22(7):pii=30465. DOI: http://dx.doi.org/10.2807/1560-7917.ES.2017.22.7.30465

The 2016/17 mid-season vaccine effectiveness estimate against influenza $\mathrm{A}\left(\mathrm{H}_{3} \mathrm{~N}_{2}\right)$ was $15 \%$ (95\% confidence interval: -11 to 35 ) in Navarre. Comparing to individuals unvaccinated in the current and four prior seasons, effectiveness was $24 \%$ for current and $3-4$ prior doses, $61 \%$ for current and $1-2$ prior doses, $42 \%$ for only current vaccination, and $58 \%$ for 3-4 prior doses. This suggests moderate effectiveness for different combinations of vaccination in the current and prior seasons.

During the early 2016/17 influenza season, influenza $\mathrm{A}\left(\mathrm{H}_{3} \mathrm{~N}_{2}\right)$ was the main circulating virus in Europe [1]. Although most of the $A\left(\mathrm{H}_{3} \mathrm{~N}_{2}\right)$ viruses characterised genetically matched the vaccine component, a high incidence of severe cases was detected $[1,2]$. We present the 2016/17 mid-season vaccine effectiveness (VE) estimates in preventing laboratory-confirmed influenza $A\left(\mathrm{H}_{3} \mathrm{~N}_{2}\right)$, relative to different combinations of current and prior seasonal influenza vaccinations.

\section{Setting and information sources}

In the $2016 / 17$ season the $\mathrm{A}\left(\mathrm{H}_{3} \mathrm{~N}_{2}\right)$ component recommended for the influenza vaccine in the northern hemisphere was A/HongKong/4801/2014-like virus (group 3C.2a) [3], in the 2015/16 season A/ Switzerland/9715293/2013-like (group 3C.3a) [4], and in seasons 2012/13 to 2014/15 it was A/Texas/50/2012like or A/Victoria/361/2011-like (group 3C.1) [5].

The Influenza Surveillance System in Spain reported that as of 9 February $2017,99 \%$ of the sentinel detections of influenza virus were $A\left(\mathrm{H}_{3} \mathrm{~N}_{2}\right)$, and sequence analysis of the $\mathrm{HA}_{1}$ fragment of the haemagglutinin gene found $74 \%$ of strains as A/Bolzano/7/2016 (group
3C.2a1) and $21 \%$ as $A /$ HongKong/4801/2014, both of which matched the vaccine component [2].

A test-negative case-control study was conducted, based on epidemiological and virological surveillance of influenza in primary healthcare and hospitals in Navarre, northern Spain. The influenza vaccination campaign took place in October and November 2016. The trivalent inactivated non-adjuvanted vaccine was offered free of charge to a target group for vaccination, including people aged 60 years or over and those with major chronic conditions (body mass index $\geq 40 \mathrm{~kg} / \mathrm{m} 2$, cancer, liver cirrhosis, dementia, diabetes mellitus, immunodeficiency, heart disease, renal disease, respiratory disease, rheumatic disease, and stroke).

Influenza vaccine status in seasons $2012 / 13$ to $2016 / 17$ was obtained from the online regional vaccination register [6]. These five seasons were considered because for all of them the $A\left(\mathrm{H}_{3} \mathrm{~N}_{2}\right)$ component included in the vaccine belonged to clade ${ }_{3} \mathrm{C}[3-5]$.

Patients were considered to be protected from influenza 14 days after vaccine administration in the current season.

Influenza surveillance was based on automatic reporting of cases of influenza-like illness (ILI) from all primary healthcare physicians and hospitals [7]. A sentinel network of primary healthcare physicians was requested to take nasopharyngeal and pharyngeal swabs from their patients diagnosed with ILI, whose symptoms had begun less than five days previously. In hospitals, the protocol specified early detection and swabbing of all hospitalised patients with ILI. Samples 
Effectiveness of current season influenza vaccination and of vaccination in the four prior seasons in preventing laboratory confirmed influenza A(H3N2) cases among people $\geq 9$ years-old in Navarre, Spain, 1 December 2016-31 January 2017 $(\mathrm{n}=1,240$ patients)

All patients

Never vaccinated

No current $+1-2$ prior doses

No current $+>2$ prior doses

Current + no prior doses

Current $+1-2$ prior doses

Current $+>2$ prior doses

Hospitalised patients

Never vaccinated

No current + 1-2 prior doses

No current $+>2$ prior doses

Current + no prior doses

Current +1-2 prior doses

Current $+>2$ prior doses

Primary healthcare patients

Never vaccinated

No current + 1-2 prior doses

No current $+>2$ prior doses

Current + no prior doses

Current + 1-2 prior doses

Current $+>2$ prior doses

$$
\begin{gathered}
303 / 230 \\
25 / 44 \\
23 / 53 \\
24 / 31 \\
21 / 50 \\
194 / 241 \\
82 \text { / } 121 \\
13 / 36 \\
18 / 48 \\
12 \text { / 15 } \\
16 / 41 \\
159 \text { / } 222 \\
221 / 109 \\
12 \text { / } 8 \\
5 \text { / } 5 \\
12 / 16 \\
5 / 9 \\
36 \text { / } 19
\end{gathered}
$$

Adjusted vaccine effectiveness, $\%(95 \% \mathrm{CI})^{\mathrm{a}}$

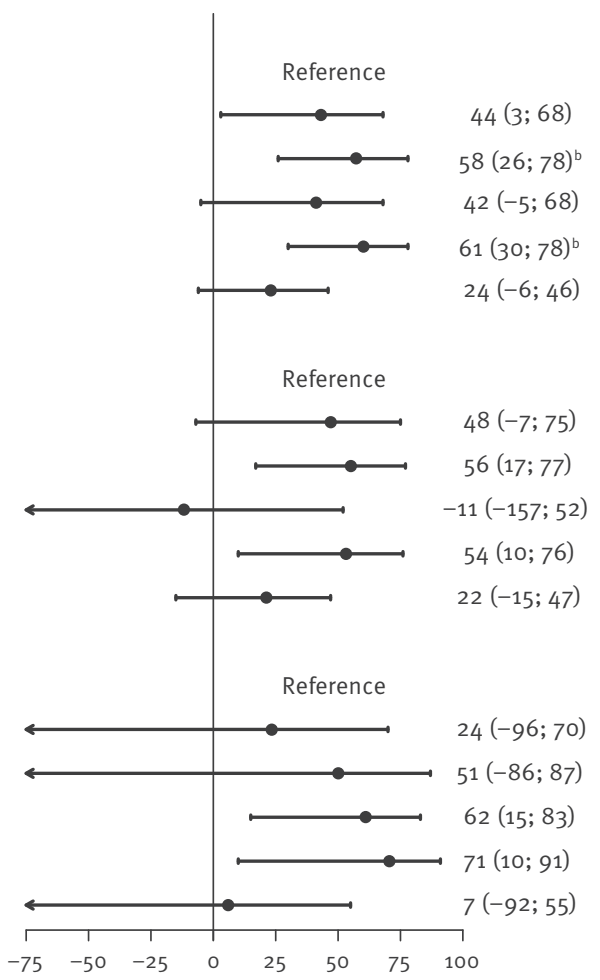

$\mathrm{Cl}$ : confidence interval.

a Vaccine effectiveness adjusted by age groups (9-24, 25-44, 45-64, 65-84 and $\geq 85$ years), sex, major chronic conditions(body mass index $\geq 40 \mathrm{~kg} / \mathrm{m} 2$, cancer, liver cirrhosis, dementia, diabetes mellitus, immunodeficiency, heart disease, renal disease, respiratory disease, rheumatic disease and stroke), healthcare setting (primary healthcare and hospital), and month of swabbing.

${ }^{b} \mathrm{p}<0.05$ for comparisons with the category 'Current season vaccination $+>2$ prior doses'.

were processed by reverse transcription-polymerase chain reaction assay.

\section{Statistical analysis}

The study population included persons covered by the Navarre Health Service since 2012 (96\% of the population). All patients who were swabbed between 1 December 2016 (beginning of continued detection of influenza virus) and 31 January 2017 were initially considered. Healthcare workers, persons living in nursing homes, children less than 9 years-old and patients hospitalised before ILI symptom onset were excluded. We compared seasonal vaccination status in patients for whom $\mathrm{A}\left(\mathrm{H}_{3} \mathrm{~N}_{2}\right)$ influenza virus was detected (cases) and in those who were negative for influenza (controls). Crude and adjusted odds ratios (OR) with their 95\% confidence intervals $(\mathrm{Cl})$ were calculated using logistic regression models. Adjusted models included sex, age group $(9-24,25-44,45-64,65-84$ and $\geq 85$ years), major chronic conditions, month of swabbing, and healthcare setting (primary healthcare and hospital). Six categories combining current vaccination status with vaccination in the four prior seasons and thus distinguishing between frequent and infrequent vaccinees were considered [8,9]: current-season vaccination and $>2$ prior doses, current-season vaccination and 1-2 prior doses, current-season vaccination and no prior doses, no current-season vaccination and $>2$ prior doses, no current-season vaccination and 1-2 prior doses, and no current-season vaccination and no prior doses (reference group). To compare VE among categories, the model was repeated using the category with current season vaccination and $>2$ prior doses as the reference. VE was estimated as a percentage: (1OR) $\times 100$.

\section{Early estimation of influenza vaccine effectiveness}

Of 1,243 ILI initial patients, one case of non-subtyped influenza A and two influenza B cases were not further 
Characteristics, according to the healthcare setting and test result, of patients with medically-attended influenza-like illness included in the test-negative case-control analysis, Navarre, Spain, 1 December 2016-31 January 2017 ( $\mathrm{n}=1,240$ patients)

\begin{tabular}{|c|c|c|c|c|c|c|c|c|c|c|c|c|}
\hline \multirow{3}{*}{ Characteristics } & \multicolumn{4}{|c|}{ All patients } & \multicolumn{4}{|c|}{ Hospitalised patients } & \multicolumn{4}{|c|}{ Primary healthcare patients } \\
\hline & \multicolumn{2}{|c|}{ Controls } & \multicolumn{2}{|c|}{ Cases } & \multicolumn{2}{|c|}{ Controls } & \multicolumn{2}{|c|}{ Cases } & \multicolumn{2}{|c|}{ Controls } & \multicolumn{2}{|c|}{ Cases } \\
\hline & $\mathrm{N}$ & $\%$ & $\mathrm{~N}$ & $\%$ & $\mathrm{~N}$ & $\%$ & $\mathrm{~N}$ & $\%$ & $\mathrm{~N}$ & $\%$ & $\mathrm{~N}$ & $\%$ \\
\hline \multicolumn{13}{|c|}{ Age groups in years } \\
\hline $9-24$ & 37 & 6 & 56 & 9 & 14 & 3 & 1 & 0 & 23 & 14 & 55 & 19 \\
\hline $25-44$ & 76 & 12 & 99 & 17 & 22 & 5 & 7 & 2 & 54 & 33 & 92 & 32 \\
\hline $45-64$ & 135 & 21 & 121 & 20 & 80 & 17 & 33 & 11 & 55 & 33 & 88 & 30 \\
\hline $65-84$ & 269 & 41 & 197 & 33 & 236 & 49 & 143 & 48 & 33 & 20 & 54 & 19 \\
\hline$\geq 85$ & 132 & 20 & 118 & 20 & 131 & 27 & 116 & 39 & 1 & 1 & 2 & 1 \\
\hline \multicolumn{13}{|l|}{ Sex } \\
\hline Male & 331 & 51 & 274 & 46 & 269 & 56 & 151 & 50 & 62 & 37 & 123 & 42 \\
\hline Female & 318 & 49 & 317 & 54 & 214 & 44 & 149 & 50 & 104 & 63 & 168 & 58 \\
\hline \multicolumn{13}{|l|}{ Residence } \\
\hline Rural & 237 & 37 & 213 & 36 & 213 & 44 & 154 & 51 & 24 & 15 & 59 & 20 \\
\hline Urban & 412 & 63 & 378 & 64 & 270 & 56 & 146 & 49 & 142 & 86 & 232 & 80 \\
\hline \multicolumn{13}{|c|}{ Major chronic conditions } \\
\hline No & 189 & 29 & 242 & 41 & 78 & 16 & 43 & 14 & 111 & 67 & 199 & 68 \\
\hline Yes & 460 & 71 & 349 & 59 & 405 & 84 & 257 & 86 & 55 & 33 & 92 & 32 \\
\hline \multicolumn{13}{|c|}{ Month of swabbing } \\
\hline December & 159 & 24 & 139 & 24 & 106 & 22 & 58 & 19 & 53 & 32 & 81 & 28 \\
\hline January & 490 & 76 & 452 & 76 & 377 & 78 & 242 & 81 & 113 & 68 & 210 & 72 \\
\hline \multicolumn{13}{|c|}{ Target group for vaccination ${ }^{\mathrm{a}}$} \\
\hline No & 124 & 19 & 182 & 31 & 36 & 7 & 11 & 4 & 88 & 53 & 171 & 59 \\
\hline Yes & 525 & 81 & 409 & 69 & 447 & 93 & 289 & 96 & 78 & 47 & 120 & 41 \\
\hline \multicolumn{13}{|c|}{$2016 / 17$ season vaccine } \\
\hline No & 327 & 50 & 351 & 59 & 205 & 42 & 113 & 38 & 122 & 73 & 238 & 82 \\
\hline Yes & 322 & 50 & 240 & 41 & 278 & 58 & 187 & 62 & 44 & 27 & 53 & 18 \\
\hline Total & 649 & 100 & 591 & 100 & 483 & 100 & 300 & 100 & 166 & 100 & 291 & 100 \\
\hline
\end{tabular}

a Target group for vaccination includes people $\geq 60$ years old and people with major chronic conditions (body mass index $\geq 40 \mathrm{~kg} / \mathrm{m}^{2}$, cancer, liver cirrhosis, dementia, diabetes mellitus, immunodeficiency, heart disease, renal disease, respiratory disease, rheumatic disease and stroke).

considered. The remaining $1,240 \mathrm{ILI}$ patients were included in the study and consisted of $783(63 \%)$ hospitalised patients and 457 primary healthcare patients. A total of 591 (48\%) were confirmed cases for influenza $\mathrm{A}\left(\mathrm{H}_{3} \mathrm{~N}_{2}\right)$ and were compared with 649 controls negative for any influenza virus.

Compared with test-negative controls, $\mathrm{A}\left(\mathrm{H}_{3} \mathrm{~N}_{2}\right)$ influenza cases had a lower proportion of persons over 65 years-old $(53 \%(315 / 591)$ in cases vs $62 \%(401 / 649)$ in controls; $p=0.003)$, with major chronic conditions ( $59 \%$ vs 71\%; $\mathrm{p}<0.001$; Table 1 ) and who were treated in hospital (51\% (300/591) vs 74\% (483/649; $p<0.001)$ ). Among the cases, $41 \%$ had received the $2016 / 17$ seasonal vaccine, vs $50 \%$ of the controls $(p=0.001)$ (Table 1).

The overall adjusted estimate of influenza VE was $15 \%$ (95\%Cl: -11 to 35 ). The estimates were similar in the analysis of the target group for vaccination (16\%), and were somewhat better in persons younger than 65 years (24\%) than in the older age group ( $\geq 65$ years; $11 \%)$. The point estimates suggested higher VE in outpatients ( $48 \% ; 95 \% \mathrm{Cl}:-1$ to 65$)$ than in inpatients (0\%; 95\% Cl: -38 to 27 ) (Table 2 ).

In the pooled analysis of all patients, as compared with individuals unvaccinated in the current and four prior seasons, the preventive effect was $61 \%$ ( $95 \% \mathrm{Cl}: 30$ to 78 ) in those vaccinated in the current season who had also received 1-2 doses of vaccine in the prior seasons, $24 \%$ (95\% Cl: -6 to 46$)$ in those vaccinated in the current season after $3-4$ doses, $42 \%(95 \% \mathrm{Cl}:-5$ to 68 ) in those vaccinated only in the current season, $58 \%(95 \% \mathrm{Cl}: 26$ to 78$)$ in individuals without current vaccination but with $>2$ prior doses, and $44 \%$ ( $95 \% \mathrm{Cl}$ : 3 to 68 ) in those unvaccinated in the current season but with 1-2 prior doses. Current and 1-2 dose prior season vaccination, or current season non-vaccination in people with $>2$ prior doses showed statistically significant higher protection than current and $>2$ prior season vaccinations (Figure). 
TABLE 2

Influenza vaccine effectiveness in preventing laboratory-confirmed influenza A(H3N2) among individuals $\geq 9$ years-old in Navarre, Spain, 1 December 2016-31 January 2017 ( $\mathrm{n}=1,240$ patients)

\begin{tabular}{|c|c|c|c|c|}
\hline Characteristics & $\begin{array}{c}\text { Controls } \\
\text { Vaccinated/unvaccinated }\end{array}$ & $\begin{array}{c}\text { Cases } \\
\text { Vaccinated/unvaccinated }\end{array}$ & $\begin{array}{l}\text { Crude VE } \\
\%(95 \% \mathrm{Cl})\end{array}$ & $\begin{array}{l}\text { Adjusted VE } \\
\%(95 \% \mathrm{Cl})^{\mathrm{a}}\end{array}$ \\
\hline \multicolumn{5}{|l|}{ Both healthcare settings } \\
\hline All swabbed patients & $322 / 327$ & $240 / 351$ & $31(13$ to 45$)$ & $15(-11$ to 35$)$ \\
\hline Target group for vaccination ${ }^{b}$ & $307 / 218$ & $225 / 184$ & $13(-13$ to 33$)$ & $16(-12$ to 37$)$ \\
\hline \multicolumn{5}{|l|}{ Age group in years } \\
\hline $9-64$ & $56 / 192$ & $37 / 239$ & $47(16$ to 66$)$ & $24(-26$ to 55$)$ \\
\hline$\geq 65$ & $266 / 135$ & $203 / 112$ & $8(-25$ to 33$)$ & $11(-23$ to 35$)$ \\
\hline \multicolumn{5}{|l|}{ Hospitalised patients } \\
\hline All swabbed patients & $278 / 205$ & $187 / 113$ & $-22(-64$ to 9$)$ & o $(-38$ to 27$)$ \\
\hline Target group for vaccination ${ }^{b}$ & $272 / 175$ & $185 / 104$ & $-14(-55$ to 16$)$ & $2(-36$ to 29$)$ \\
\hline \multicolumn{5}{|l|}{ Age group in years } \\
\hline $9-64$ & $33 / 83$ & $14 / 27$ & $-30(-179$ to 39$)$ & $-27(-188$ to 44$)$ \\
\hline$\geq 65$ & $245 / 122$ & $173 / 86$ & o (-40 to 29$)$ & $5(-34$ to 33$)$ \\
\hline \multicolumn{5}{|l|}{ Primary healthcare patients } \\
\hline All swabbed patients & $44 / 122$ & $53 / 238$ & 38 (3 to 61$)$ & $48(-1$ to 65$)$ \\
\hline Target group for vaccination ${ }^{b}$ & $35 / 43$ & $40 / 80$ & $39(-10$ to 66$)$ & 54 (10 to 77$)$ \\
\hline \multicolumn{5}{|l|}{ Age group in years } \\
\hline $9-64$ & $23 / 109$ & $23 / 212$ & 49 (4 to 72$)$ & $43(-8$ to 70$)$ \\
\hline$\geq 65$ & $21 / 13$ & $30 / 26$ & $29(-70$ to 70$)$ & $44(-41$ to 78$)$ \\
\hline
\end{tabular}

$\mathrm{Cl}$ : confidence interval; VE: vaccine effectiveness.

a Logistic regression model adjusted for sex, age group (9-24, 25-44, 45-64, 65-85 and $\geq 85$ years), major chronic conditions, month of swabbing and healthcare setting (primary healthcare and hospital).

b Target group for vaccination includes people $\geq 60$ years old and people with major chronic conditions (body mass index $\geq 40 \mathrm{~kg} / \mathrm{m}^{2}$, cancer, liver cirrhosis, dementia, diabetes mellitus, immunodeficiency, heart disease, renal disease, respiratory disease, rheumatic disease and stroke).

In separated analyses of outpatients and inpatients, vaccination only in the current season was protective for primary healthcare consultations but not for hospitalisations. In hospitalised patients however, a history of vaccination in the prior seasons appeared to confer enhanced protection, whether the inpatients were vaccinated or not in the current season (Figure).

\section{Discussion and conclusion}

Estimates of VE during the influenza season help guide health interventions aimed at reducing the impact of influenza in the population [10] and may help in the selection of strains to be contained in the next season's vaccine. For the $2016 / 17$ season in Navarre, when vaccination status in the prior influenza seasons was not considered, we found low VE (15\%) in the whole pool of patients, null VE for hospitalised patients and better protection (48\%) for outpatients; the higher protection level in outpatients is consistent with the early estimates reported from the Canadian Sentinel Practitioner Surveillance Network [11].

In the analysis considering vaccination history; however, better levels of protection were observed for many of the combinations of current and prior season vaccination, especially for hospitalised patients. The results of the overall analysis suggest that the protective effect of the influenza vaccination against $\mathrm{A}\left(\mathrm{H}_{3} \mathrm{~N}_{2}\right)$ virus in Navarre in the early 2016/17 season ranged from $24 \%$ to $61 \%$, depending on the vaccination status in the current and prior seasons.

The VE estimates were strongly related to the vaccination history. One or two vaccine doses over the four prior seasons maintained or increased the protection of the current season vaccination, but three or more prior doses had a negative interference with the current season vaccine effect. A similar interference was described in previous seasons by other authors $[8,12]$, and inverse exposure-response association has been reported between repeated influenza vaccination and haemagglutinin antibodies titres for $\mathrm{A}\left(\mathrm{H}_{3} \mathrm{~N}_{2}\right)$ virus [13].

Our results obtained from two independently recruited groups, inpatients and outpatients, were broadly consistent. The main difference was that vaccination only in the current season was protective for influenza cases attended in primary healthcare but not against influenza hospitalisations, which may be due to the poorer immune response among patients that need hospitalisation. Especially remarkable is the preventive effect observed for the vaccine doses received in prior seasons in individuals without current season vaccination. 
This study has some limitations. Natural immunity due to exposure to influenza virus was not considered; however, in a previous study we demonstrated that it was not a relevant confounding factor or effect modifier of influenza VE [7]. Since these results are preliminary and have limited statistical power for some analyses, the final results for the season may be different. The study compared laboratory-confirmed cases with controls recruited in the same settings before either patient or physician knew the laboratory result, an approach that reduced selection bias [14]. We included patients recruited in primary care and hospitals, thus achieving representation of the whole spectrum of patients with influenza. The healthcare setting could have acted as a confounding factor, therefore the analyses were adjusted for this variable. This study evaluates a particular situation of circulating virus and composition of the vaccines; caution should be taken in generalising its outcome.

In conclusion, the results suggest that, overall, the different combinations of vaccination in the current and prior seasons were moderately effective against influenza $A\left(\mathrm{H}_{3} \mathrm{~N}_{2}\right)$ in the early $2016 / 17$ season in northern Spain. In spite of the possible interferences between the effects of the current season vaccine and frequent prior vaccination, these findings highlight the net benefit of immunisation against influenza.

\section{Primary Health Care Sentinel Network of Navarre}

The members of the Primary Health Care Sentinel Network of Navarre are: I Abad, P Aldaz, R Ansorena, I Arceiz, E Arina, MA Arrechea, I Arribas, MD Artajo, B Azagra, N Aznarez, FC Bartolome, A Beguiristain, A Beltrán, M Bidarte, I Blanco, A Brugos, B Cano, MV Castresana, JC Cenoz, F Cia, B Compains, JR Corpas, F Cortés, B Churío, PC Cuevas, EM Da Costa, MR Díez, FJ Escribano, MJ Esparza, V Etayo, C Fernández Alfaro, B Flamarique, ML Garcés, FJ García Nicolás, AB German, A Giner, JO Guiu, JC Gurbindo, MJ Guruchaga, JA Heras, M Hernández Galindo, MC Hijos, S Indurain, B Iñigo, MC Irigoyen, JJ Jurio, MJ Lizaso, JJ Longás, MJ López, MT Maquirriain, M Mazquiaran, JJ Miner, M Moreno, MA Moros, U Navarro, M Orte, M Oscoz, P Palacio, J Palau, C Pérez Lecumberri, P Pérez Pascual, B Pérez Sanz, A Prado Virto, M Prado Santamaria, A Puig Arrastia M Ramos, BE Rípodas, M Rodríguez, MA Roncal, I Ruiz Puertas, C Sánchez, P Sarrasqueta, F Satrústegui, MA Senosiain, M Sota, ME Ursua, IA Urtasun, M Zardoya, ME Zubieta, F Elia, E Albeniz.

Network for Influenza Surveillance in Hospitals of Navarre

The members of the Network for Influenza Surveillance in Hospitals of Navarre are: A Navascués, P Artajo, C Beaumont, X Beristain, J Chamorro, C Ezpeleta, F Gallinas, F Gil, M Herranz, J Hueto, C Martín, L Moreno, S MartínezPérez, C Pérez, J Sesma (Complejo Hospitalario de Navarra), MT Ortega, JJ García Irure, M Torres (Hospital Reina Sofía, Tudela), F Lameiro, L Barrado, E Martín (Hospital García Orcoyen, Estella), M Arriazu, M Garcia Cenoz, A Barricarte, J Castilla (Instituto de Salud Pública de Navarra).
Acknowledgements

This study was supported by the Horizon 2020 program of the European Commission (agreement 634446); by the I-MOVE (Influenza Monitoring Vaccine Effectiveness in Europe) Network funded by the European Centre for Disease Prevention and Control; by La Caixa Foundation; and by the Carlos III Institute of Health with the European Regional Development Fund (ERDF) (CM15/o0119, INT15/00182).

\section{Conflict of interest}

None declared.

\section{Authors' contributions}

J Castilla, I Casado and I Martínez-Baz designed the study and coordinated the activities. I Martínez-Baz, I Casado and J Castilla undertook the statistical analysis. A Navascués, A Aguinaga, A Pérez-García, C Ezpeleta and F Pozo were responsible of the virological analysis and the interpretation of laboratory results. J Díaz-González, L Fernandino and I Casado participated in the data collection. J Castilla, C Ezpeleta, F Pozo and I Martínez-Baz wrote the draft manuscript, and all authors revised and approved the final version.

\section{References}

1. European Centre for Disease prevention and Control (ECDC). Risk assessment of seasonal influenza, EU/EEA, 2016-2017 - Update, 25 January 2017. Stockholm: ECDC; 2017. Available from: http://ecdc.europa.eu/en/publications/Publications/ Risk-assessment-seasonal-influenza-2016-2017-update.pdf

2. Sistema de Vigilancia de la Gripe en España. Informe semanal de Vigilancia de la Gripe en España. Semana 5/2017 No 494. [Weekly report of the influenza surveillance system in Spain 5/2017. No 494]. Madrid: Instituto de Salud Carlos III; 9 February 2017. Spanish. Available from: http://vgripe.isciii.es/ gripe/documentos/20162017/boletines/grn052017.pdf

3. Recommended composition of influenza virus vaccines for use in the 2016-2017 northern hemisphere influenza season. Wkly Epidemiol Rec. 2016;91(10):121-32.PMID: 26971356

4. Recommended composition of influenza virus vaccines for use in the 2015-2016 northern hemisphere influenza season. Wkly Epidemiol Rec. 2015;90(11):97-108.PMID: 25771542

5. Recommended composition of influenza virus vaccines for use in the 2014-2015 northern hemisphere influenza season. Wkly Epidemiol Rec. 2014;89(10):93-104.PMID: 24707514

6. Aguilar I, Reyes M, Martínez-Baz I, Guevara M, Albéniz E, Belza $M$, et al. Use of the vaccination register to evaluate influenza vaccine coverage in seniors in the 2010/11 influenza season, Navarre, Spain. Euro Surveill. 2012;17(17):20154.PMID: 22551499

7. Castilla J, Navascués A, Fernández-Alonso M, Reina G, Albéniz E, Pozo F, et al. , Primary Health Care Sentinel Network and Network for Influenza Surveillance in Hospitals of Navarra. Effects of previous episodes of influenza and vaccination in preventing laboratory-confirmed influenza in Navarre, Spain, 2013/14 season.Euro Surveill. 2016;20(22):30243.DOI: 10.2807/1560-7917.ES.2016.21.22.30243 PMID: 27277013

8. McLean HQ, Thompson MG, Sundaram ME, Meece JK, McClure $\mathrm{DL}$, Friedrich TC, et al. Impact of repeated vaccination on vaccine effectiveness against influenza $A\left(\mathrm{H}_{3} \mathrm{~N}_{2}\right)$ and $B$ during 8 seasons. Clin Infect Dis. 2014:59(10):1375-85. DOI: 10.1093/cid/ ciu680 PMID: 25270645

9. Martínez-Baz I, Casado I, Navascués A, Díaz-González I, Aguinaga A, Barrado L, et al. Effect of repeated vaccination with the same vaccine component against influenza $A\left(\mathrm{H}_{1} \mathrm{~N}_{1}\right)$ pdm09. J Infect Dis. 2017; (Forthcoming). DOI: 10.1093/infdis/ jix055 PMID: 28170032

10. Valenciano M, Ciancio B, I-MOVE study team. I-MOVE: a European network to measure the effectiveness of influenza vaccines.Euro Surveill. 2012;17(39):20281.PMID: 23041022

11. Skowronski DM, Chambers C, Sabaiduc S, Dickinson JA, Winter A, De Serres G, et al. Interim estimates of 2016/17 vaccine effectiveness against influenza $\mathrm{A}\left(\mathrm{H}_{3} \mathrm{~N}_{2}\right)$, Canada, January 2017. Euro Surveill. 2017;22(6):30460. 
12. Ohmit SE, Petrie JG, Malosh RE, Fry AM, Thompson MG,

Monto AS. Influenza vaccine effectiveness in households

with children during the 2012-2013 season: assessments of prior vaccination and serologic susceptibility.J Infect Dis. 2015;211(10):1519-28. DOI: 10.1093/infdis/jiu650 PMID: 25416812

13. Thompson MG, Naleway A, Fry AM, Ball S, Spencer SM, Reynolds S, et al. Effects of repeated annual inactivated influenza vaccination among healthcare personnel on serum hemagglutination inhibition antibody response to $\mathrm{A} /$ Perth/16/2009 ( $\left.\mathrm{H}_{3} \mathrm{~N}_{2}\right)$-like virus during 2010-11. Vaccine. 2016;34(7):981-8. DOI: 10.1016/j.vaccine.2015.10.119 PMID: 26813801

14. Valenciano M, Kissling E, Ciancio BC, Moren A. Study designs for timely estimation of influenza vaccine effectiveness using European sentinel practitioner networks.Vaccine. 2010;28(46):7381-8. DOI: 10.1016/j.vaccine.2010.09.010 PMID: 20851086

\section{License and copyright}

This is an open-access article distributed under the terms of the Creative Commons Attribution (CC BY 4.0) Licence. You may share and adapt the material, but must give appropriate credit to the source, provide a link to the licence, and indicate if changes were made.

This article is copyright of the authors, 2017. 